\title{
Payment Reform Needed to Address Health Disparities of Undiagnosed Diabetic Retinopathy in the City of Chicago
}

\author{
Dustin D. French • Jess J. Behrens · Kathryn L. Jackson • Abel N. Kho • \\ Theresa L. Walunas · Charlesnika T. Evans · Michael Mbagwu • \\ Curtis E. Margo $\cdot$ Paul J. Bryar
}

Received: October 14, 2016/ Published online: November 24, 2016

(C) The Author(s) 2016. This article is published with open access at Springerlink.com

\section{ABSTRACT}

Introduction: The Affordable Care Act (ACA) has expanded health coverage for thousands of Illinois residents. Expanded coverage, however, does not guarantee appropriate health care. Diabetes and its ocular complications serve as

Enhanced content To view enhanced content for this article, go to http://www.medengine.com/Redeem/B32 7F06060F24265.

D. D. French $(\bowtie) \cdot$ M. Mbagwu · P. J. Bryar Department of Ophthalmology, Center for Healthcare Studies, Northwestern University Feinberg School of Medicine, Chicago, IL, USA e-mail: Dustin.French@northwestern.edu

D. D. French · C. T. Evans

Department of Veterans Affairs, Center of Innovation for Complex Chronic Healthcare, Edward Hines, Jr. VA Hospital, Hines, IL, USA

J. J. Behrens · K. L. Jackson · A. N. Kho ·

T. L. Walunas

Department of Medicine, and Center for Health Information Partnerships, Northwestern University

Feinberg School of Medicine, Chicago, IL, USA

\section{T. Evans}

Department of Preventive Medicine, Center for Healthcare Studies, Northwestern University

Feinberg School of Medicine, Chicago, IL, USA

\section{E. Margo}

Department of Ophthalmology Morsani College of Medicine, University of South Florida, Tampa, FL, USA an example of how providers in underserved urban areas may not be able to keep up with new demand for labor- and technology-intensive health care unless changes in reimbursement policies are instituted.

Methods: A retrospective cohort study was conducted using medical encounter information from the Chicago HealthLNK Data Repository (HDR), an assembly of non-duplicated and de-identified patient medical records. We used a method of estimating the geographic distribution of undiagnosed diabetic retinopathy in the city of Chicago to illustrate the magnitude of potentially preventable eye disease. All rates were calculated for all ZIP Codes within Chicago (Cook County), and statistical differences between observed and geographically adjusted expected rates $(p<0.10, p<0.05, p<0.01)$ were highlighted as underserved areas.

Results: This analysis included 150,661 patients with diabetes identified from a total of nearly two million patients in Chicago. High rates of undetected diabetic retinopathy were found in low-income and minority areas. 
Within these areas, $37 \%$ of the identified diabetics were uninsured, with rates ranging widely from $20 \%$ to $68.6 \%$. Among those with insurance, $32.8 \%$ were covered by Medicare and only $10 \%$ by Medicaid. Most patients with untreated diabetic retinopathy were found to reside in areas where primary health care is provided through Federally Qualified Health Centers.

Conclusions: With 150,661 diabetics identified in the city of Chicago, and this number continuing to rise each year, a manpower approach with ophthalmologist screening for diabetic retinopathy is not realistic. The ability to identify the growing number of diabetic patients with retinopathy in low-income areas will likely require the adoption of cost-effective screening technologies that are currently not funded by Medicare and Medicaid.

Keywords: Diabetes; Disparities

Ophthalmology; Physician payment;

Policy; Retinopathy; Telehealth

\section{INTRODUCTION}

As a result of the Affordable Care Act (ACA), thousands of Illinois residents are now able to receive health insurance and medical care. Estimates of increased health coverage for Illinois parallel those of other states, with a $17 \%$ increase in Medicaid recipients from July 2013 to December 2015 [1]. Large metropolitan areas such as Chicago are likely to notice the greatest impact in new patients, since they have a substantial number of previously uninsured individuals. Chicago is the third largest city in the United States, with a population of over 2.7 million, among which more than 20\% are uninsured [2]. Although an increasing number of minorities in selected areas of Chicago will now be enrolled in Medicaid, this may not guarantee access to care or appropriate referral to specialists, simply due to an insufficient number providers who accept this form of insurance [3]. The lack of resources common in underserved urban areas may also impede the use of labor- and technology-intensive screening interventions. The situation among patients with diabetes and its complications may serve as an example to facilitate a better understanding of how large numbers of patients in underserved areas are affected by these phenomena.

Persons with diabetes are at risk for diabetic eye disease, most importantly diabetic retinopathy. Among those with diagnosed diabetes, the prevalence of diabetic retinopathy is $9.9 \%$ [5], which translates to over 4.4 million Americans aged 40 years and older [4]. If undetected or untreated, diabetic retinopathy can lead to blindness. Timely detection and treatment, however, substantially reduces the risk of visual loss [6]. Vision loss and blindness are preventable in many diabetics if appropriate and accessible screening and medical care are available. It is understandable, therefore, that low-income and minority populations (often uninsured) are at greater risk of diabetic eye disease than the general population [7-9]. Compared to whites, African Americans have a higher incidence of diabetic retinopathy $(38.8 \%$ vs. $26.4 \%)$ and vision-threatening diabetic eye disease $(9.3 \%$ vs. 3.2\%) [10]. Research has shown that the risk of vision loss due to diabetic retinopathy can be reduced with early detection and treatment; however, diabetic retinopathy remains the leading cause of new cases of legal blindness in persons between the ages of 20 and 74 [10].

The purpose of this study was to estimate the geographic distribution of undiagnosed diabetic 
retinopathy among residents of the city of Chicago using a city-wide health data repository for pre-ACA years 2006-2012. Targeting areas with the greatest health care disparities for diabetic eye care should help in formulating policies that optimize limited resources.

\section{METHODS}

\section{Study Design}

A retrospective cohort study was conducted using medical encounter information from the Chicago HealthLNK Data Repository (HDR), an assembly of non-duplicated and de-identified patient medical records. The HDR includes nearly six million unique patients, of which nearly 2.7 million reside in Chicago [11]. These data are restricted to adults aged 18-89 years, and contain primarily structured data elements. The HDR assembly includes electronic health records from six health care institutions: five large academic medical centers (Northwestern Medicine, University of Chicago Hospitals and Clinic, Rush University Medical Center, University of Illinois at Chicago Medical Center, and Loyola University Medical Center) and one large county health care system (Cook County Health and Hospital Systems) [11]. Data extractions from all of the participating academic medical centers include specific standardized data elements. For this study, the variables included demographics, vital signs (such as height, weight, and blood pressure), diagnoses and procedure codes, health insurance type (uninsured, Medicaid, Medicare, or private insurance), linkable study identification number, visit or service date, encounter type, encounter number, provider type and location name, and patient home location (ZIP Code), among others. We obtained pre-ACA electronic data for calendar years 2006 through 2012. The study was reviewed and approved by the Northwestern University Institutional Review Board.

\section{Statistical Analysis}

We utilized geographic mapping methods to determine statistically significant "hot spots" of undiagnosed diabetic retinopathy within ZIP Codes in the city of Chicago [12-21]. First, we identified patients with diabetes and diabetic retinopathy through our health information exchange using the International Classification of Diseases, Ninth Revision (ICD-9), diagnosis codes and the Current Procedural Terminology Fourth Edition (CPT) codes. Details of the patients' ZIP Code of residence, age, gender, race, and insurance status were retained for geographic adjustment, as these factors may influence health care-seeking behavior [22-25]. The observed numbers of patients in the HDR with these conditions were compared to what would be an expected number of patients with diabetes and diabetic retinopathy using published disease rates controlled by ZIP Code demographics with Tele Atlas ${ }^{\mathrm{TM}}[5,26]$.

The ratio of cases of diabetic retinopathy to cases of diabetes was compared with the expected ratio to test the null hypothesis of no difference between the observed and expected ratios of diabetic retinopathy. A health disparity or underserved area was identified when the observed rate was lower than the expected rate while controlling for age, gender, race, and insurance status. The adjustments employed a spatial adjustment factor for estimated cases (denominator) in each ZIP Code relative to its gravity or influences of age, gender, race, insurance status, and population density. The population-weighted centroid for each was 
calculated using 2010 US Census total population estimates by geographically associated US block groups in 250 ZIP Codes in and around the Chicago area.

ArcGIS 10.3 software was used for all calculations and cartographic work [26]. An inverse distance-weighted approach was then applied within the two-step methodology to calculate gravity scores for each ZIP Code [12-15]. The average score value (measure of health care access) was then determined and divided into the scores for each study area ZIP Code. This produced a multiplier for estimated cases by ZIP Code that was less than 1 in ZIP Codes with less gravity when compared to the average, and larger than 1 when ZIP Code weight was larger than the average. Estimated cases (denominator) by ZIP Code within Cook County were then adjusted using the gravity multiplier for diabetes and diabetic retinopathy. All rates were calculated for all ZIP Codes within Chicago (Cook County), and statistical differences between observed and geographically adjusted expected rates $(p<0.10, p<0.05, p<0.01)$ were highlighted as underserved areas.

\section{Compliance with Ethics Guidelines}

Ethics approval was obtained through the Northwestern University Institutional Review Board, identification number STU00201551-CR 0001.

\section{RESULTS}

This analysis included 150,661 patients with diabetes identified from a total of nearly two million patients in Chicago. Figure 1 shows the hot spots of diabetes and diabetic retinopathy throughout the city of Chicago. The areas shaded in red represent statistically significant differences between the actual and expected rates of diabetic retinopathy, where potentially large numbers of patients with diabetic retinopathy were undiagnosed and thus presumably not treated. These areas include 21 ZIP Codes and neighborhoods known as the South Loop, Far South, Near West, and Far West with respect to downtown Chicago. We estimate that the overall rate of untreated diabetic retinopathy within hotspot areas is $10 \%$. This amounts to 3220 cases that, if left untreated, could lead to long-term vision loss.

Within hotspots, $37 \%$ of the identified diabetics were uninsured, with the rates of uninsured individuals ranging widely from $20 \%$ to $68.6 \%$. Among those insured, $32.8 \%$ were covered by Medicare and only $10 \%$ by Medicaid. The mean age ( \pm standard deviation) of diabetics in hot spots was $62( \pm 14)$ years. Over $90 \%$ of the identified diabetics were African American, 4.5\% were white, 2.3\% were Hispanic, and $3.2 \%$ other race/ethnicity.

Figure 1 shows hatched areas that represent the top $20 \%$ with the highest density of patients with diabetes in the city of Chicago. Some of the hatched areas with high rates of diabetes do not have statistically significant differences in undetected diabetic retinopathy. These non-shaded but hatched areas illustrate the income disparity across the downtown area, from affluent to varying degrees of impoverishment. In contrast, the population in more affluent areas is mostly white (70.1\%), with a $90 \%$ insured rate (and $7.9 \%$ with diabetic retinopathy).

The majority of the hotspots of areas with high rates of undetected diabetic retinopathy occurred in low-income and minority areas. The Federally Qualified Health Centers (FQHCs) were superimposed on the map as green dots. These FQHCs predominately serve minorities and the uninsured patients. As shown in Fig. 1, 


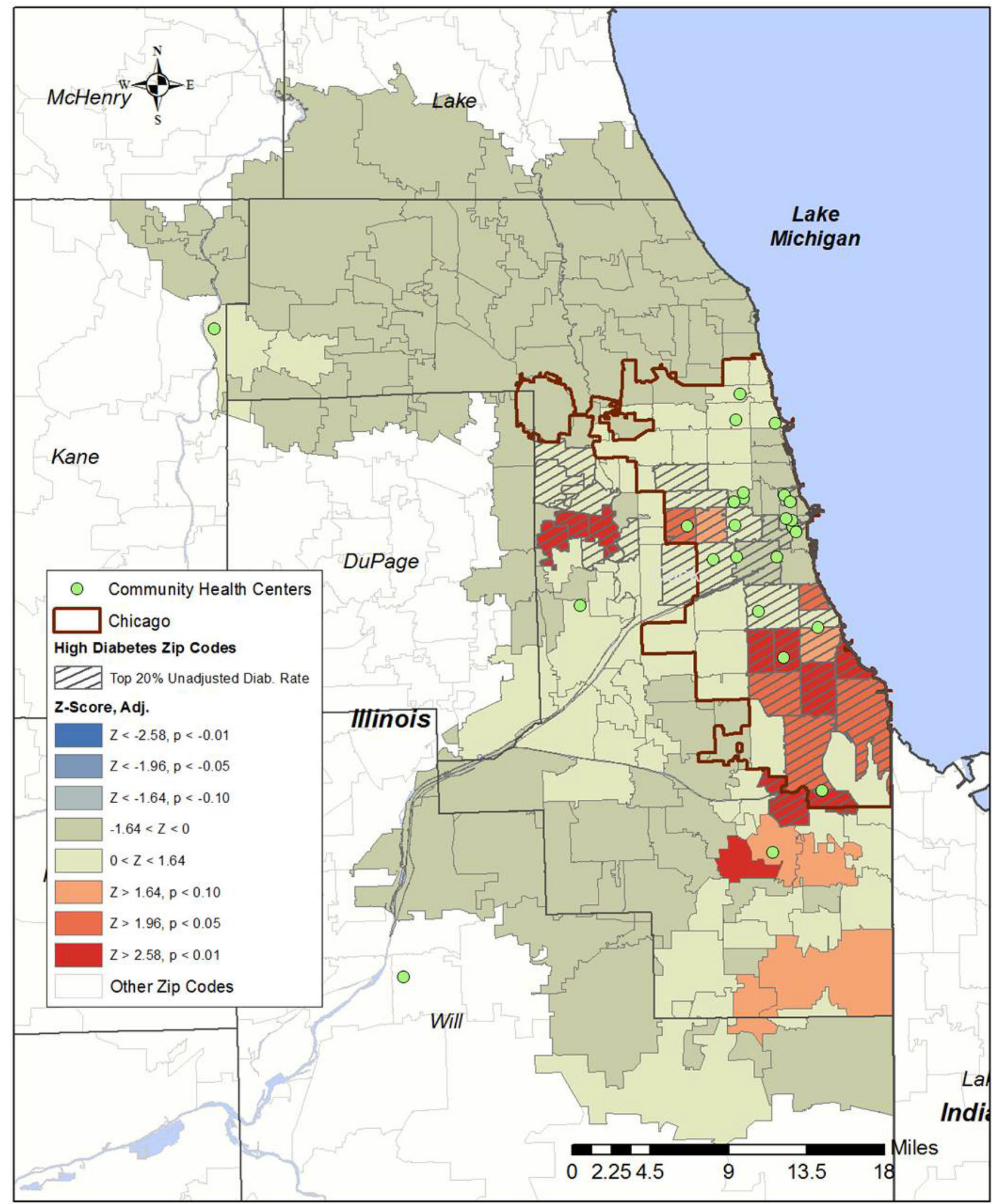

Fig. 1 Adjusted gravity model hotspot analysis of undiagnosed diabetic retinopathy for 2006-2012 
most patients with untreated diabetic retinopathy reside in areas where primary health care is provided through FQHCs.

\section{DISCUSSION}

Disparities in eye care are a manifestation of multiple social and economic factors, most notably inadequate or no health insurance and lack of access to eye care professionals [22-25]. The FQHCs are a critical component of the national health care safety net [27]. Many FQHC patients are minorities who do not have insurance or are recent Medicaid enrollees. Without these centers, many would likely lack access to medical care. The FQHCs provide standardized care and are strategically positioned in communities where minorities and the under-insured live [28].

For over 15 years, Northwestern Medicine has funded and implemented programs to provide on-site screening at some of these FQHCs, and has provided subspecialty care and surgical services for many of these patients in need of treatment for diabetic eye disease. Currently, three ophthalmologists and one optometrist screen and treat patients on-site at FQHCs on a weekly basis. With the potential increase in diabetic eye care predicted by this study as a result of the Medicaid expansion, the current workforce and practicing ophthalmologists may not be adequate to deal with the growing need (Fig. 1). More efficient methods of screening and detection of diabetic eye disease are needed to address this health care disparity in low-income and minority patients. While Illinois Medicaid does cover the treatment of diabetic eye disease (eye surgery, laser, and medications) [29], disparities in diabetic eye care still exist.

One of the goals of the Healthy People 2020 initiative is to reduce visual impairment related to diabetic retinopathy [30]. To this end, the National Eye Institute's 2012 strategic plan includes "expand[ed] efforts in telemedicine to manage retinal diseases like diabetic retinopathy...via web-based networks" [31]. Research has shown that telemedicine increases access to specialists for populations in rural and/or underserved areas, at a considerable cost savings [32]. Among the many facets of telemedicine is teleophthalmology, which includes retinal fundus examination. While a dilated eye exam with an eye care provider is considered the "gold standard" for detecting diabetic retinopathy, an alternative-but equally effective-method of diabetic eye disease screening is through a digital photograph of the retina.

Digital retinal photography with a non-mydriatic (undilated pupil) camera can be completed in about a minute's time by clinic support staff during a primary care visit, and then viewed online remotely by an ophthalmologist. Studies have shown that digital photography is as effective as a dilated eye exam, and patients with vision-threatening disease can be rapidly identified and promptly referred for examination and management $[32,33]$. The broad range of telemedicine technologies and protocols for diabetic retinopathy reflects progressive improvement in diagnostic sensitivity and specificity, with enhanced cost-effectiveness [34, 35]. The operational and clinical components of telemedicine programs for diabetic retinopathy were recently reviewed, and the logistical advantages of such programs were consistently acknowledged [33, 34].

Although telemedicine technology is available, however, current reimbursement under Medicaid and Medicare does not address payment for obtaining and interpreting images 
taken from non-mydriatic cameras if done so for screening diabetics for eye disease [32, 33, 36-39]. Without payment reform, it is unlikely that the goals of Healthy People 2020 and the National Eye Institute's strategic plan can be achieved in professionally underserved areas. Ironically, other federally financed health care programs such as the Veterans Health Administration and the Indian Health Service have successfully used telehealth technology for diabetic retinopathy screening and other specialty care for some time [32, 33, 36-39]. A key difference is the perceived distinction between Medicaid and Medicare as "private sector" enterprises versus veteran and Indian health care as federally financed entitlement programs.

\section{Limitations}

There are several limitations to our analysis. First, the results obtained for the city of Chicago may not be reflective of other large cities. However, Chicago is one of the largest cities in the USA, with a diverse population, making this study generalizable to other diverse urban cities. Another limitation is that the HDR does not capture all practices and is not a sample of the entire city. Our map only allowed us to examine geographic statistical areas in the pre-ACA era. We could not account for eye care provided outside the FQHC, though that likelihood is low given the traditionally larger out-of-pocket costs for private screening in both the pre- and now post-ACA era.

\section{CONCLUSIONS}

Our study shows that in Chicago, a large proportion of unscreened patients with diabetes have undiagnosed diabetic retinopathy. The ability to screen the growing number of patients with diabetes in low-income areas will likely require adoption of cost-effective screening technologies. This in turn will be contingent upon Medicare and Medicaid payment reform that incentivizes the use of validated screening techniques $[32,33]$ in appropriate settings.

\section{ACKNOWLEDGEMENTS}

This research was supported by an unrestricted grant from Research to Prevent Blindness, New York, NY, and the Department of Health and Human Services National Institutes of Health, National Eye Institute Grant Number 1R21EY024050-01A1, "Understanding Diabetic Eye Disease in the Underserved Using Health Data Exchange." All named authors meet the International Committee of Medical Journal Editors (ICMJE) criteria for authorship for this manuscript, take responsibility for the integrity of the work as a whole, and have given final approval for the version to be published. All authors contributed to the conception and design of the study and interpretation of the data. K.L. Jackson, A.N. Kho, and T.L. Walunas contributed to the acquisition of data. J.J. Behrens and K.L. Jackson contributed to the management of the study analysis. D.D. French drafted the manuscript. All authors contributed to the writing, editing, and approval of the final version of the manuscript.

Disclosures. Dustin D. French, Jess J. Behrens, Kathryn L. Jackson, Abel N. Kho, Theresa L. Walunas, Charlesnika T. Evans, Michael Mbagwu, Curtis E. Margo, and Paul J. Bryar have nothing to disclose.

Compliance with Ethics Guidelines. Ethics approval was obtained through the 
Northwestern University Institutional Review Board, identification number STU00201551-CR 0001.

Data Availability. The datasets generated and/or analyzed during the current study are available from the corresponding author on reasonable request.

Open Access. This article is distributed under the terms of the Creative Commons Attribution-NonCommercial 4.0 International License (http://creativecommons.org/licenses/ by-nc/4.0/), which permits any noncommercial use, distribution, and reproduction in any medium, provided you give appropriate credit to the original author(s) and the source, provide a link to the Creative Commons license, and indicate if changes were made.

\section{REFERENCES}

1. Medicaid.gov Keeping America Healthy, Illinois [Internet]. Centers for Medicare \& Medicaid Services. https://www.medicaid.gov/medicaidchip-program-information/by-state/illinois.html. Accessed 16 Mar 2016.

2. United States Census Bureau [Internet]. QuickFacts Cook County, Illinois. http://www.census.gov/ quickfacts/table/HEA775214/17031. Accessed 16 Mar 2016.

3. Geissler KH, Lubin B, Marzilli Ericson KM. Access is not enough: characteristics of physicians who treat medicaid patients. Med Care. 2016;54:350-8.

4. Vision Problems in the U.S. Prevalence of Adult Vision Impairment and Age-Related Eye Disease in America 2008 Update [internet]. http://www. preventblindness.net/site/DocServer/VPUS_2008_ update.pdf. Accessed 16 Mar 2016.

5. Zhang X, Saaddine JB, Chou CF, Cotch MF, Cheng YJ, Geiss LS, et al. Prevalence of diabetic retinopathy in the United States, 2005-2008. JAMA. 2010;304:649-56.

6. National Eye Institute. National Institutes of Health [internet]. Facts About Diabetic Eye Disease. https:// nei.nih.gov/health/diabetic/retinopathy. Accessed 16 Mar 2016.

7. Ryskulova A, Turczyn K, Makuc DM, Cotch MF, Klein RJ, Janiszewski R. Self-reported age-related eye diseases and visual impairment in the United States: results of the 2002 national health interview survey. Am J Public Health. 2008;98:454-61.

8. Tanna AP, Kaye HS. Trends in self-reported visual impairment in the United States: 1984 to 2010. Ophthalmology. 2012;119:2028-32.

9. Zhang X, Saaddine JB, Lee PP, Grabowski DC, Kanjilal S, Duenas MR, et al. Eye care in the United States: do we deliver to high risk people who can benefit the most from it? Arch Ophthalmol. 2007;25:411-8.

10. French DD, Margo CE, Tanna AP, Volpe NJ, Rubenstein LZ. Associations of Injurious Falls and Self-Reported Incapacities: Analysis of the National Health Interview Survey. J Patient Saf. 2014 (Epub ahead of print).

11. Kho AN, Cashy JP, Jackson KL, Pah AR, Goel S, Boehnke J. Design and implementation of a privacy preserving electronic health record linkage tool in Chicago. J Am Med Inform Assoc. 2015;22:1072-80.

12. Luo W, Qui Y. An enhanced two-step floating catchment area (E2SFCA) method for measuring spatial accessibility to primary care physicians. Health Place. 2009; 15:1100-7.

13. Nqui AN, Apparicio P. Optimizing the two-step floating catchment area method for measuring spatial accessibility to medical clinics in Montreal. BMC Health Serv Res. 2011;11:166.

14. McGrail MR, Humphrey JS. Measuring spatial accessibility to primary care in rural areas: improving the effectiveness of the two-step floating catchment area method. Appl Geogr. 2009;29:533-41.

15. McGrail MR. Spatial accessibility of primary health care utilising the two step floating catchment area method: an assessment of recent improvements. Int J Health Geogr. 2012;11:50.

16. Field KS, Briggs DJ. Socio-economic and locational determinants of accessibility and utilization of primary health-care. Health Soc Care Community. 2001;9:294-308.

17. Fryer GE Jr, Drisko J, Krugman RD, Vojir CP, Prochazka A, Miyoshi TJ, et al. Multi-method assessment of access to primary medical care in rural Colorado. J Rural Health. 1999;15:113-21. 
18. Ricketts TC, Goldsmith LJ, Holmes GM, Randolph $\mathrm{RM}$, Lee R, Taylor DH, et al. Designating places and populations as medically underserved: a proposal for a new approach. J Health Care Poor Underserved. 2007;18:567-89.

19. Fortney J, Rost K, Warren J. Comparing alternative methods of measuring geographic access to health services. Health Serv Outcomes Res Method. 2000;1:173-84.

20. Wright RA, Andres TL, Davidson AJ. Finding the medically underserved: a need to revise the federal definition. J Health Care Poor Underserved. 1996;7:296-307.

21. Joseph AE, Phillips DR. Accessibility and utilization: Geographical perspectives on health care delivery. New York: Harper and Row; 1984.

22. Lee DJ, Lam BL, Arora S, Arheart KL, McCollister KE, Zheng DD, et al. Reported eye care utilization and health insurance status among US adults. Arch Ophthalmol. 2009;127:303-10.

23. Chou CF, Barker LE, Crews JE, Primo SA, Zhang X, Elliott $\mathrm{AF}$, et al. Disparities in eye care utilization among the United States adults with visual impairment: findings from the behavioral risk factor surveillance system 2006-2009. Am J Ophthalmol. 2012;154:S45-52.

24. Lam BL, Lee DJ, Zheng DD, Davila EP, Christ SL, Arheart KL. Disparity in prevalence of self-reported visual impairment in older adults among US race-ethnic subgroups. Ophthalmic Epidemiol. 2009;16:144-50.

25. Zambelli-Weiner A, Crews JE, Friedman DS. Disparities in adult vision health in the United States. Am J Ophthalmol. 2012;154:S23-30.

26. ESRI [Internet]. Tele Atlas and Products for ArcGIS. http://www.esri.com/data/streetmap. Accessed 31 Mar 2016.

27. US Department of Health and Human Services [Internet]. Health Center Program. What is a Health Center? http://bphc.hrsa.gov/about/whatis-a-health-center/index.html. Accessed 1 Apr 2016.

28. Near North Health Services Corporation [Internet]. About Near North. http://www.nearnorthhealth. org/\#!about/c24ja. Accessed 1 Apr 2016.

29. Illinois Department of Healthcare and Family Services [Internet]. Enter drug name to search below. http://ilpriorauth.com/Default.aspx. Accessed 1 Apr 2016.
30. Office of Disease Prevention and Health Promotion [Internet]. V-5.2 Reduce visual impairment due to diabetic retinopathy. https://www.healthypeople. gov/2020/topics-objectives/topic/vision/objectives? topicId=42. Accessed 1 Apr 2016.

31. National Eye Institute. National Institutes of Health [Internet]. Vision Research: Needs, Gaps, and Opportunities. National Eye Institute. 2012. https://nei.nih.gov/sites/default/files/nei-pdfs/Vision Research2012.pdf. Accessed 1 Apr 2016.

32. Zhang W, Nicholas P, Schuman SG, et al. Screening for diabetic retinopathy using a portable, noncontact, nonmydriatic handheld retinal camera. J Diabetes Sci Technol. 2016. pii:1932296816658902. (Epub ahead of print).

33. Shi L, Wu H, Dong J, et al. Telemedicine for detecting diabetic retinopathy: a systematic review and meta-analysis. $\mathrm{Br} \mathrm{J}$ Ophthalmol. 2015;99(6):823-31.

34. Horton MB, Silva PS, Cavallerano JD, Aiello LP. Clinical components telemedicine programs for diabetic retinopathy. Curr Diab Rep. 2016;16:129. doi:10.1007/s11892-016-0813-8.

35. Horton MD. Silva, Cavallerano, Aiello LP. Operation components of telemedicine programs for diabetic retinopathy. Curr Diab Rep. 2016;16:128. doi:10.1007/s11892-0016-0814-7.

36. Cavallerano AA, Conlin PR. Teleretinal imaging to screen for diabetic retinopathy in the Veterans Health Administration. J Diabetes Sci Technol. 2008;2:33-9.

37. Conlin PR, Fisch BM, Orcutt JC, Hetrick BJ, Darkins AW. Framework for national teleretinal imaging program to screen for diabetic retinopathy in Veterans Health Administration patients. J Rehabil Res Dev. 2006;43:741-8.

38. The Role of Telehealth in an Evolving Health Care Environment: Workshop Summary. Board on Health Care Services; Institute of Medicine. Washington (DC): National Academies Press (US); 2012 [Internet]. http://www.ncbi.nlm.nih.gov/ books/NBK207133/. Accessed 1 Apr 2016.

39. Owsley C, McGwin G Jr, Lee DJ, Lam BL, Friedman DS, Gower EW, et al. Diabetes eye screening in urban settings serving minority populations: detection of diabetic retinopathy and other ocular findings using telemedicine. JAMA Ophthalmol. 2015;133:174-81. 